\title{
The changes in the geographical patterns of China's tourism in 1978-2018: Characteristics and underlying factors
}

\author{
ZHANG Chengming ${ }^{1,3}$, WENG Shixiu ${ }^{1,3},{ }^{*}$ BAO Jigang ${ }^{2,3}$ \\ 1. School of Geography and Planning, Sun Yat-sen University, Guangzhou 510275, China; \\ 2. School of Tourism Management, Sun Yat-sen University, Guangzhou 510275, China; \\ 3. Center for Tourism Planning \& Research, Sun Yat-sen University, Guangzhou 510275, China
}

\begin{abstract}
Since the reform and opening-up policy launched in 1978, the number of inbound tourists increased from 1.8 million in 1978 to 139.5 million in 2017 , and that of domestic tourists increased from 344 million in 1991 to 5 billion in 2017. This article conducts research on how the geographical pattern of China's tourism has evolved in the last four decades on the national-scale and regional-scale, for rare studies before could focus on such an extended date and utilize inbound and domestic tourism data simultaneously. Grounded on viable datasets and multiple vibrant data analysis approaches (including the Gini coefficient, primacy index analysis, hot spot analysis and Pearson correlation analysis), this article unpacks triple vital realities. (1) The overall geographical pattern of China's tourism development can arguably summarize as "high in the eastern and low in the western part, high in the southern and low in the northern part." Meanwhile, China's inbound tourism has long shown a pattern of polarized distribution; While, domestic tourism has experienced a shift from the polarized distribution to the equilibrium distribution. (2) According to the features and characteristics, China's tourism development can be divided into four stages. They are precisely the initial modern tourism stage (1978-1988), the domestic tourism cultivating stage (1989-1996), the rapid development stage (1997-2007) and the new normal stage (2008-present). (3) This article also identified multiple factors underlying the inbound and domestic tourism development in China, including policies, management systems, tourism demand, tourist attractions, economic level, consumption level, industrial development, investment status, traffic conditions, accommodation services, intermediary services and degree of openness.
\end{abstract}

Keywords: reform and opening-up; tourism development; spatial pattern; development stage; influencing factor; China

Received: 2019-08-10 Accepted: 2019-09-30

Foundation: National Natural Science Foundation of China, No.41571137

Author: Zhang Chengming (1989-), PhD Candidate, specialized in elite landscape and tourism destination evolution. E-mail: zhangchm@qq.com; zhangchm5@mail2.sysu.edu.cn

"Corresponding author: Bao Jigang (1964-), PhD and Professor, specialized in regional development and tourism planning. E-mail: eesbjg@mail.sysu.edu.cn 


\section{Introduction}

In the past 40 years of reform and opening-up, China's tourism industry has shifted from solely focusing on inbound tourism to developing both inbound tourism and domestic tourism, and further to concurrently developing domestic tourism, inbound tourism and outbound tourism. According to statistics, the number of inbound tourists was 139 million in 2017, which was 77 times that of 1978; the number of domestic tourists was 5 billion, which was 14.5 times that of 1991 . The outbound tourists reached 129 million, and the outbound tourism consumption reached $\$ 115.29$ billion in 2017. China will not only become the world's largest tourist country and the fourth most significant source of tourists by 2020 (UNWTO, 2009), but also China's tourism development has aroused attention worldwide.

Spatiotemporal pattern of China's tourism is a traditional research topic, and studies on this topic have achieved fruitful results. On the spatial scale, these studies could be divided into the regional-scale and national-scale. Regional-scale studies would regularly apply several kinds of tourism data (e.g. inbound tourist, tourism foreign exchange, domestic tourist or domestic tourism income) to analyze the tourism spatiotemporal pattern of one urban agglomeration (Chen et al., 2011; Cao et al., 2012) or one single province (Shi et al., 2007; Li et al., 2013; Ma et al., 2015). These studies observed and analyzed consecutive years' changes in tourism pattern in one region or province; however, they lacked a national-scale perspective for the tourism pattern of the whole of China. The national-scale studies could synthetically analyze the changes in tourism pattern of thorough China; however, the data utilized in those studies were always limited to inbound tourist data (Ma and Li, 2001; Liu et al., 2010; Li et al., 2012) and tourism foreign exchange (Guo et al., 2014; Wang et al., 2014). Only a few articles would refer to data of domestic tourist (Yang and Wong, 2013) or perspective of the high-speed railway network (Wang et al., 2018).

Given that tourism is a complex economic phenomenon and it is difficult to fully reflect the real situation of tourism development by using a single index (Wang et al., 2014), it is necessary to apply multiple data to research the tourism pattern of China on the national-scale. On the time-scale, this article finds that the previous studies could be classified into static studies of one single year (Liu et al., 2010; Wang et al., 2018), cross-sectional studies of several interval years (Chen et al., 2011; Zhang et al., 2013) and dynamic studies of successive years (Cao et al., 2012; Li et al., 2012; Guo et al., 2014). Also, even the dynamic studies in successive years only discussed the evolution of tourism pattern within 10 years or so (Li et al., 2012; Huang et al., 2013; Yang and Wong, 2013; Wang et al., 2014), few studies discussed the evolution of tourism pattern over a more extended period.

For the reasons above, based on the data of inbound tourists for the period 1979-2017 and the data of domestic tourists for 1991-2017, this article attempts to sort out the characteristics and causes of China's tourism geographical pattern in the past 40 years from a national-scale perspective. The Gini coefficient, primacy index analysis and hot spot analysis are employed to map China's tourism geographical pattern, and Pearson correlation analysis is utilized to analyze the influencing factors of China's tourism development. Standing at the critical historic node of the 40 years of reform and opening-up, this article aims to make an academic supplement to the study of geographical pattern in China's tourism, and it also provides a useful summary and guidance for the development of tourism industry in China. 


\section{Data sources and methods}

\subsection{Data sources}

This study mainly analyzes the data of inbound tourists for the period from 1979 to 2017 and the data of domestic tourists for the period from 1991 to 2017. The provincial-scale data of inbound tourists and domestic tourists collected from the Yearbook of Tourism Statistics (1980-2018) and Statistical Yearbook (1980-2018) of every province in China. Besides, data of tourism foreign exchange, domestic tourism income, outbound tourists and outbound tourism consumption used in some sections also collected from the Yearbook of Tourism Statistics and Statistical Yearbook of every province. Among the data, provincial data do not contain data from Hong Kong, Macao and Taiwan. Because Hainan Province established in 1988, data of Hainan Province for the period 1979-1987 are not available. Besides, for convenience of expression, the inbound tourist in this article refers to inbound overnight tourist.

The national-scale data come from the China Statistical Yearbook. Among them, the national-scale data in 2017 collected from the Statistical Bulletin of National Economic and Social Development. Map data for Figures 1, 9 and 10 collected from the national primary geographic information database (scale 1:4 million). The data of specific variables in Table 1 collected from the China Statistical Yearbook (1992-2018) and the Yearbook of Tourism Statistics (1992-2018). The specific variables in Table 2 collected from the China Statistical Yearbook 2016 and the Yearbook of Tourism Statistics 2016.

\subsection{Methods}

\subsubsection{Gini coefficient}

Gini coefficient is a universal index to measure economic inequality in the world. This study uses it to measure the degree of imbalance in China's tourism geographical pattern. The mean difference method is often applied to calculate the Gini coefficient with discrete data (He and Hong, 2016), as shown in formula (1):

$$
G=\frac{1}{2 n^{2} \mu_{y}} \sum_{i=1}^{n} \sum_{j=1}^{n}\left|y_{i}-y_{j}\right|
$$

where $n$ is the total number of areas, $\mu_{y}$ is the average income of all areas, $y_{i}$ and $y_{j}$ are the income of area $i$ and $j$. In this study, $n$ is the number of provincial administrative units, $\mu_{y}$ is the average of inbound tourists in all provinces, $y_{i}$ and $y_{j}$ are the number of inbound tourists in province $i$ and $j$, respectively. With this formula, the Gini coefficient of inbound tourists is calculated. Similarly, the Gini coefficient of domestic tourists is also calculated. According to the United Nations Development Program, if the Gini coefficient exceeds 0.4, there is a serious "gap between the wealthy and the poor" (Wikipedia, 2018).

\subsubsection{Hot spot analysis}

Hot spot analysis can calculate Getis-Ord $\mathrm{Gi}^{*}$ statistics for attribute values of elements, and $\mathrm{Z}$-score and p-value can know the location of high-value or low-value elements in spatial clustering. $G i^{*}$ is calculated as formula (2), where $x_{j}$ is the attribute value of factor $j, W_{i, j}$ is the spatial weight of elements $i$ and $j$, and $n$ is the total number of elements (ArcGIS, 2018). 


$$
\begin{gathered}
G_{i}^{*}=\frac{\sum_{j=1}^{n} w_{i, j} x_{j}-\bar{X} \sum_{j=1}^{n} w_{i, j}}{s \sqrt{\frac{\left[n \sum_{j=1}^{n} w_{i, j}^{2}-\left(\sum_{j=1}^{n} w_{i, j}\right)^{2}\right]}{n-1}}} \\
\bar{X}=\frac{\sum_{j=1}^{n} x_{j}}{n} \\
S=\sqrt{\frac{\sum_{j=1}^{n} x_{j}^{2}}{n}-(\bar{X})^{2}}
\end{gathered}
$$

The specific calling path in the ArcGIS 10.1 platform is Arctoolbox-Spatial Statistics Analysis-Mapping Cluster-Hot Spot Analysis. In the visualization of results, Natural Breaks is used. This classification method can classify the similarity values most appropriately and maximize the differences among different classes. Moreover, the $G_{i}{ }^{*}$ were classified into three tiers by using Natural Breaks in this article. The first tier stands for the highest $G_{i}{ }^{*}$ score, that is to say, the provinces of the first tier have the highest tourist number. Likewise, the provinces of the second tier and the third tier stand for the higher tourist number and the lowest tourist number, respectively.

\subsubsection{Primacy analysis}

In 1939, American scholar Jefferson put forward the concept of "primate city" and defined the ratio of the largest city to the second largest city in population as the primacy index. According to experience, a reasonable primacy index should be 2 . If $2>$ primacy index $>1$, it indicates that the primacy distribution is not significant; if $4 \geqslant$ primacy index $>2$, the primacy distribution is moderate; if primacy index $>4$, the primacy distribution is high (Lei and Kang, 2010). In this study, the primacy index was applied to analyze the primacy distribution of inbound tourists and domestic tourists at the provincial-scale each year.

\subsubsection{The division of spatial regions in China}

According to the criteria for the division of China's economic zones during the Seventh Five-Year Plan period, in the east-west direction, this study divides China into eastern, central and western regions. As shown in Figure 1a, the eastern region includes 12 provincial level districts, namely, Liaoning, Beijing, Tianjin, Hebei, Shandong, Jiangsu, Shanghai, Zhejiang, Fujian, Guangdong, Guangxi and Hainan. The central region includes 9 provincial level districts, namely, Heilongjiang, Jilin, Inner Mongolia, Shanxi, Henan, Anhui, Hubei, Hunan and Jiangxi, and the western region includes 10 provincial level districts, namely, Xinjiang, Gansu, Ningxia, Shaanxi, Tibet, Qinghai, Sichuan, Chongqing, Yunnan and Guizhou.

In the south-north direction, this study divides China into southern and northern regions by the "Qinling Mountains-Huaihe River" line. As shown in Figure 1b, the southern region includes 15 provincial level districts, namely, Sichuan, Chongqing, Hubei, Anhui, Jiangsu, 
Shanghai, Yunnan, Guizhou, Hunan, Jiangxi, Zhejiang, Guangxi, Guangdong, Fujian and Hainan, and the northern region includes 16 provincial level districts, namely, Xinjiang, Inner Mongolia, Heilongjiang, Jilin, Liaoning, Tibet, Qinghai, Gansu, Ningxia, Shaanxi, Shanxi, Hebei, Henan, Beijing, Tianjin and Shandong.

(a)

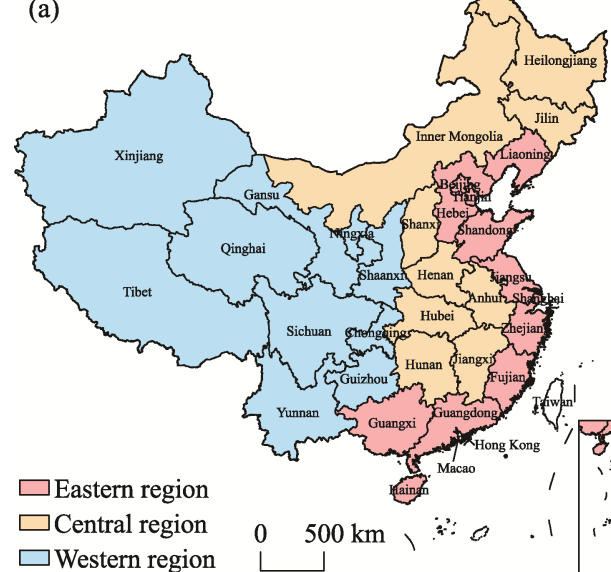

(b)

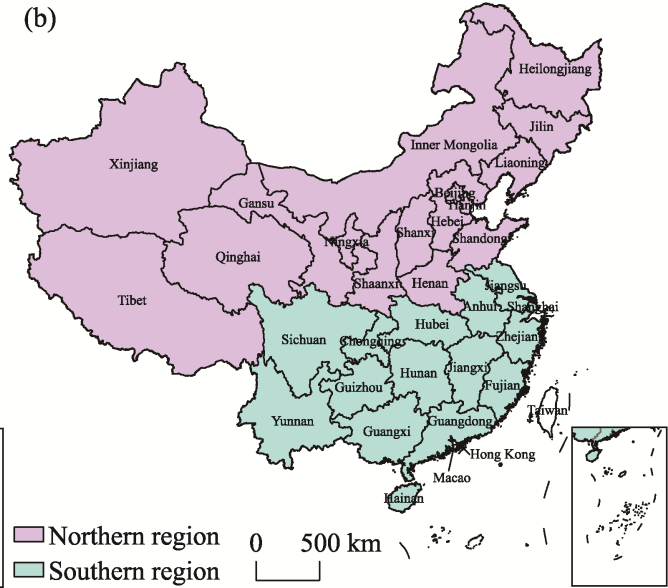

Figure 1 The division of regions in China

\section{Overall characteristics}

\subsection{The geographical pattern of tourism is "high in the eastern and low in the western part; high in the southern and low in the northern part."}

\subsubsection{High in the eastern and low in the western part}

In terms of inbound tourists, as shown in Figure 2a, the eastern region accounted for above $70 \%$ of inbound tourists of the country for a long time since 1979. Although the proportion of inbound tourists in the central and western regions has increased year by year, the sum value of the two regions has not exceeded $30 \%$ of the total number. In addition, for a long time (1987-2007), the proportion of inbound tourists in the western region was higher than that in the central region. As to domestic tourist data, as shown in Figure 2b, since 1991, the domestic tourists in the eastern region has maintained above $40 \%$ of the total number; those of the central and western regions have maintained below $30 \%$, respectively. Although the proportion of the central and western regions has increased year by year, the proportion over the years is eastern $>$ central $>$ western. Therefore, in general, the geographical pattern in China's tourism shows the characteristic of "high in the eastern and low in the western part."

\subsubsection{High in the southern and low in the northern part}

From the perspective of inbound tourists, as shown in Figure 3a, since 1979, the proportion of inbound tourists in the southern region has maintained above $70 \%$ of inbound tourists of China for a long time, and it has never been more than $30 \%$ in the northern region. As for domestic tourists, as shown in Figure 3b, since 1991, the proportion of domestic tourists in the southern region has been above $55 \%$ for a long time, and domestic tourists in the northern region were still below $45 \%$ in recent years. Overall, the tourism geographical pattern in China shows the characteristic of "high in the southern and low in the northern part." 

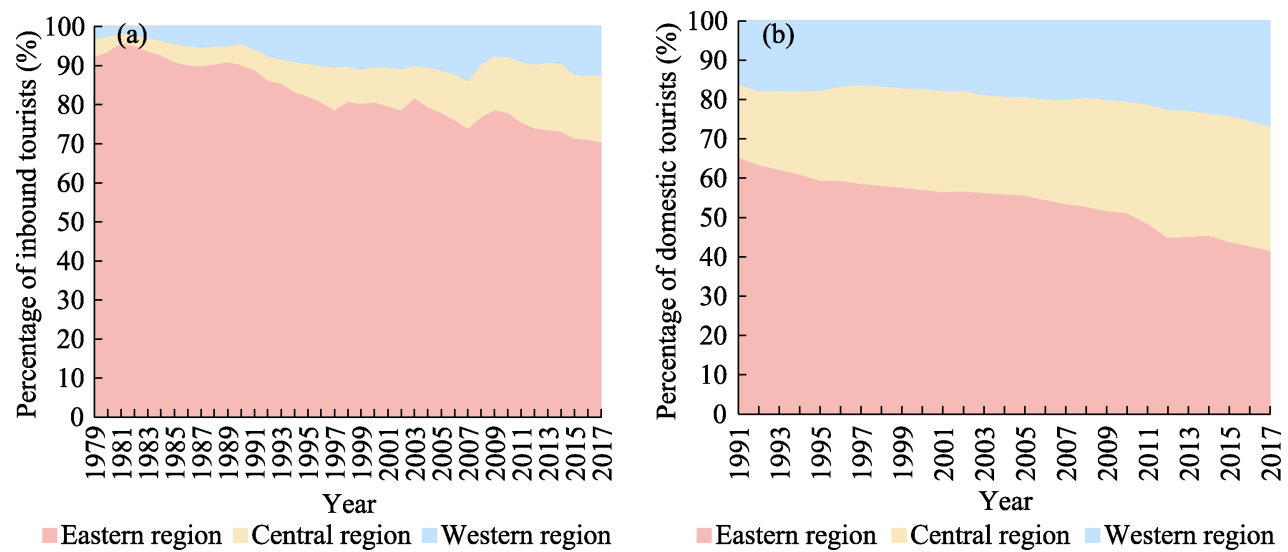

Figure 2 The proportion of inbound tourists (a) and domestic tourists (b) in eastern, central and western regions in China
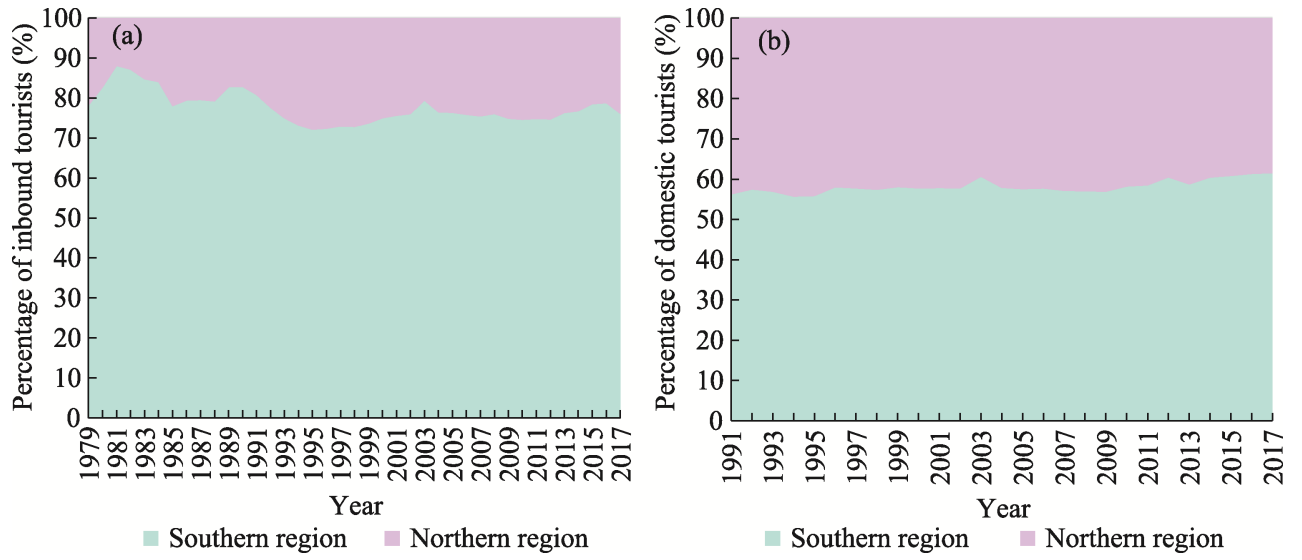

Figure 3 Proportion of inbound tourists (a) and domestic tourists (b) in southern and northern regions in China

\subsection{Polarized distribution of inbound tourism}

\subsubsection{Inbound tourism presents a polarized distribution}

By calculating the Gini coefficient of inbound tourists and inbound tourism foreign exchange earnings, as shown in Figure 4a, the Gini coefficient of inbound tourists was higher than 0.7 and once reached 0.85 before 1990. Since then, it has been varying between 0.55 and 0.7. The Gini coefficient of tourism foreign exchange earnings was above 0.8 and even once close to 0.9 before 1990 . Since then it maintained above 0.6 for a long time. As mentioned in the methods (section 2.2), if the Gini coefficient exceeds 0.4 , there is a serious "gap between the wealthy and the poor" (Wikipedia, 2018). Therefore, for the past 40 years, China's inbound tourism has been maintaining a characteristic of polarized distribution. Besides, the Gini coefficient of inbound tourists has been decreasing by 0.007 per year, and the Gini coefficient of inbound tourism foreign exchange earnings has been decreasing by 0.008 per year.

3.2.2 Guangdong is the "polar core" of inbound tourism

Guangdong always ranks first in the inbound tourists. The provinces in the second place 
have changed over time. As shown in Figure 5, the minimum value of the primacy index of the provincial inbound tourists is 3 , the maximum value is 9.27 , and the mean value is 4.65 . The primacy index is greater than 4 for nearly 30 years, indicating a high degree of primacy distribution, and between 3 to 4 for 10 years, indicating a moderate degree of primacy distribution. Also, through statistics of the distribution of inbound tourists in various provinces, Guangdong, as the province with the most significant number of inbound tourists in the past few years, occupies a dominant position in the development of inbound tourism within China. From 1979 to 2017, the proportion of Guangdong in inbound tourists range from $63.77 \%$ to $29.70 \%$. Although the proportion is declining, compared with the other 30 provincial level districts, Guangdong has always accounted for a large proportion of inbound tourists. In short, the primate province is Guangdong, and the inbound tourists in all the previous years show a high primacy distribution.
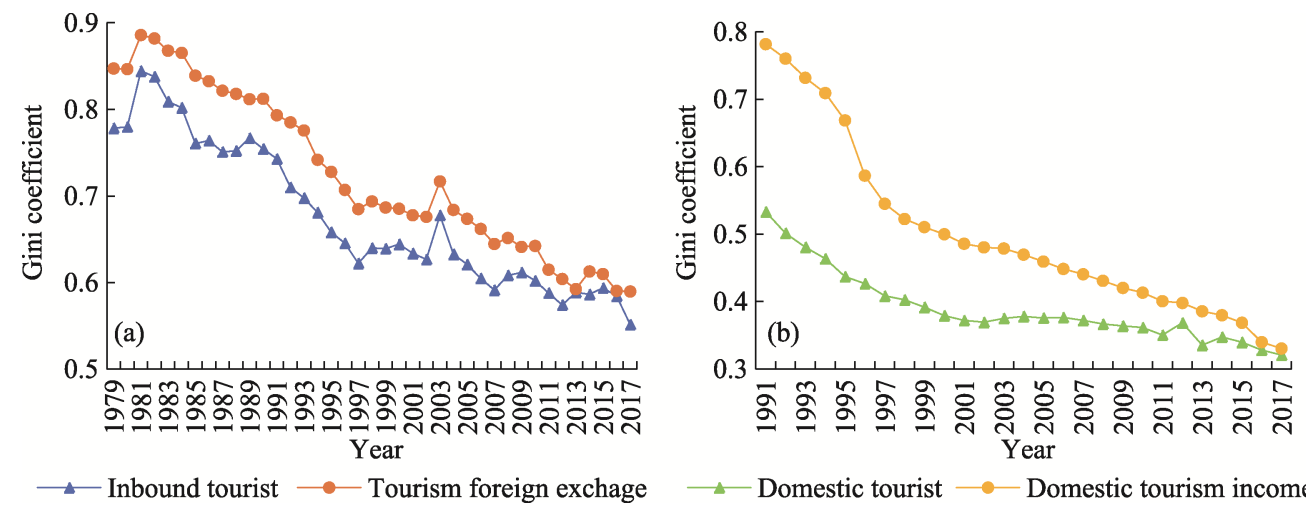

Figure 4 Inbound tourism Gini coefficient (a) and domestic tourism Gini coefficient (b) in China

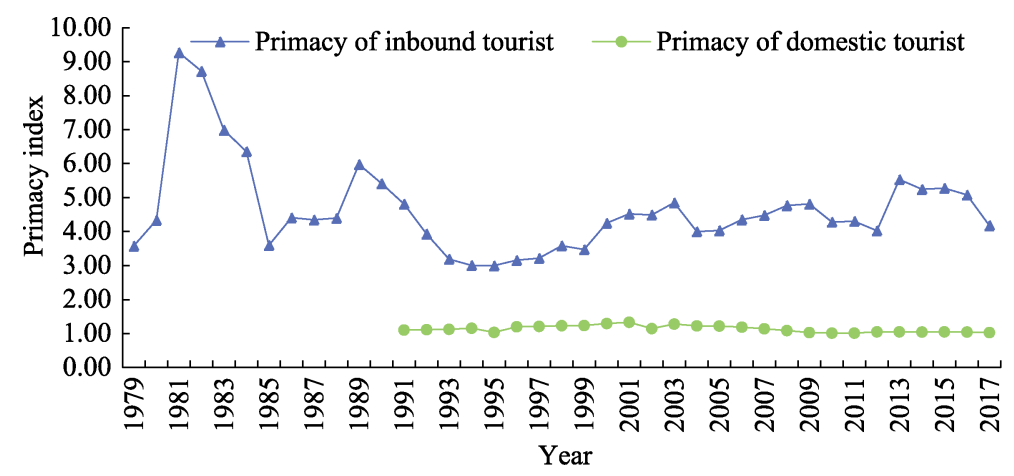

Figure 5 Provincial primacy index for inbound and domestic tourists in China

\subsection{Domestic tourism from polarized distribution to equilibrium distribution}

3.3.1 The Gini coefficient of domestic tourism gradually decreases

As shown in Figure $4 \mathrm{~b}$, the domestic tourism of China was at the polarized distribution stage before 1997, when the Gini coefficient of domestic tourists was higher than 0.4. Since 1998, the Gini coefficient gradually decreased, fluctuated between 0.35 and 0.3 in recent years, and gradually approached 0.3 , tending to be equilibrium distribution. The Gini coefficient of domestic tourism income is higher, which is above 0.55 before 1997, while the Gini coeffi- 
cient of domestic tourism income has fallen sharply. Since 1998, it has been steadily decreasing year by year, and the Gini coefficient dropped to below 0.4 in 2011. In a word, the polarization of domestic tourism in the early days has changed into a relatively balanced development in recent years.

3.3.2 The primacy distribution of domestic tourists is not significant

For domestic tourists, the primate provinces in different periods have changed over time, and the primate provinces have changed from Beijing to Jiangsu, then to Shandong. The secondary provinces are different in different periods. As shown in Figure 5, the minimum value of provincial tourists' primacy index is 1.01 , the maximum value is 1.33 , and the mean value is 1.14 . The primacy index is less than 2 . It shows that the primacy distribution of domestic tourists is not significant. Therefore, from the perspective of primacy index, the distribution of domestic tourists is relatively balanced.

\subsection{Differences of tourism development among different regions}

\subsubsection{The distribution of inbound tourists is quite different}

Inbound tourism in eastern, western, southern and northern regions are in polarized distribution. As shown in Figure 6a, the Gini coefficient of inbound tourists from the eastern, western, southern and northern regions has remained above 0.4 for the past 40 years. Polarization in the eastern and southern regions is due to the high proportion in inbound tourists of Guangdong as a "polar core" for a long time. Over the years, Guangdong has occupied more than $40 \%$ of inbound tourists in the eastern and southern regions. The main reason for polarization distribution in the western and northern is that the development of inbound tourism in Gansu, Xinjiang, Qinghai, Ningxia and Tibet is relatively slow. The total number of inbound tourists in these five provinces is less than $20 \%$ of that in the western region and less than $10 \%$ of that in the northern region. The development of tourism in the central region is relatively balanced. The Gini coefficient of inbound tourists in central China has increased over a while and remained below 0.4 for the past 40 years, without severe polarization distribution.

The primacy distribution of inbound tourists in different regions is different, and the primacy index is decreasing year by year. As shown in Figure 7a, the inbound tourists fluctuate significantly from 1 to 10.73 , indicating that the distribution of inbound tourists in different regions shows apparent differences. In the east-west direction, the primacy index of the eastern region is the highest. In the eastern region, the primacy index ranges from 3.00 to 9.27 , with an average value of 4.65 , which is the high degree of primacy distribution, indicating a high concentration of inbound tourists. The primacy index in the western and central regions is between 1and 2 for most of the time, that is, the distribution of inbound tourists is relatively balanced. In the north-south direction, the primacy index in the southern region is higher than that in the northern region. The primacy index in the southern region ranges from 4 to 10.74 , with an average value of 5.50, indicating a high degree of primacy distribution. The primacy index in the northern region is between 4 and 8.13 in all years before 1996, indicating a high primacy distribution. In the period from 1997 to 2006, the primacy index in the northern region was between 2 and 4, indicating a moderate primacy distribution. Since 2007 , the primacy index gradually reduced to 1 , showing insignificant primacy distribution. 


\subsubsection{Relatively balanced distribution of domestic tourists}

Domestic tourists in the western and northern regions present a polarized distribution. As shown in Figure 6b, the Gini coefficient of domestic tourists in these two regions has been higher than 0.4 for a long time in the past 27 years, which means that there is a severely polarized distribution in these two regions. The polarization of domestic tourists in the western and northern regions is due to the relatively slow development of Gansu, Xinjiang, Ningxia, Qinghai and Tibet. Over the years, the total number of domestic tourists in these five provinces does not exceed $13 \%$ of that in the western region and $10 \%$ of that in the northern region. The development of domestic tourism in the eastern, central and southern regions is balanced. The Gini coefficients of domestic tourists of the three regions are below 0.4 for all years except for a quite few years when it exceeds 0.4, suggesting that the development of tourism in these three regions is relatively balanced.

Primacy distribution of domestic tourists in all regions is not significant, and the primacy index is decreasing year by year. As shown in Figure $7 \mathrm{~b}$, the primacy index of domestic tourists in each region is almost between 1 and 2, indicating that domestic tourists in each region are not concentrated and relatively balanced. It is noteworthy that the primacy index of the western region is the largest in almost every year, and is more than 2 in 2006 and 2007, reaching a moderate primacy distribution. However, since 2006, the primacy index of domestic tourists has gradually decreased to 1 , that is, primacy distribution of domestic tourists in the western region is not very significant.

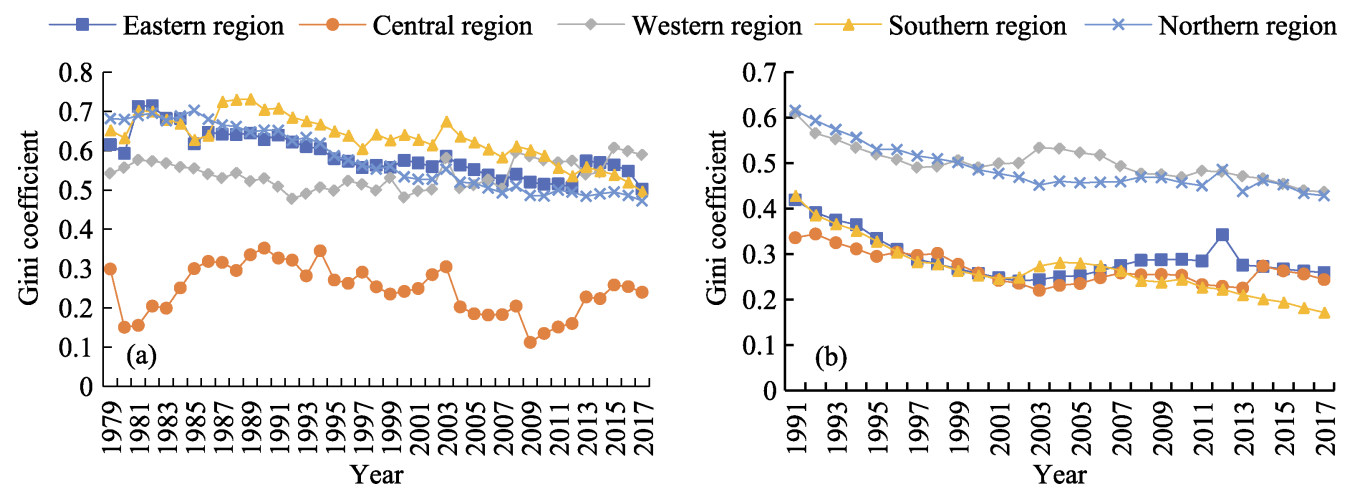

Figure 6 Gini coefficients of inbound tourists (a) and domestic tourists (b) in different regions in China
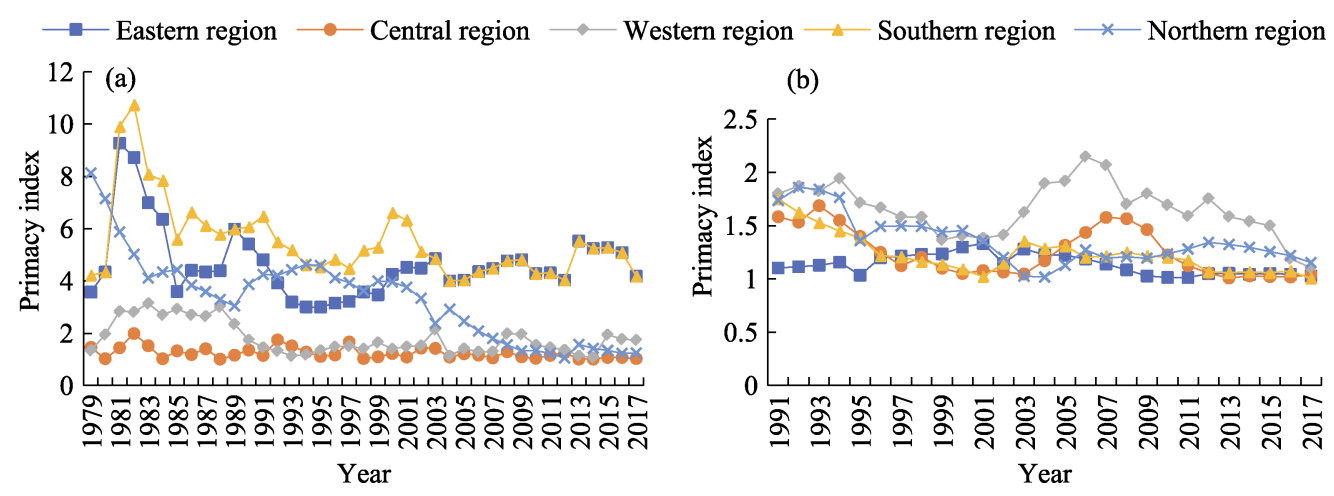

Figure 7 Provincial primacy index of inbound tourists (a) and domestic tourists (b) in different regions in China 


\subsection{Changes in tourism rankings}

As shown in Table 3, the top 5 provinces of inbound tourists (IT) in 2017 were: Guangdong $(36.48 \mathrm{M})>$ Shanghai $(8.73 \mathrm{M})>$ Fujian $(6.92 \mathrm{M})>$ Yunnan $(6.68 \mathrm{M})>$ Zhejiang $(5.89 \mathrm{M})$, respectively. And the top 5 provinces of tourism foreign exchange (TFE) in 2017 were: Guangdong $(\$ 19.65 \mathrm{~B})>$ Zhejiang $(\$ 8.28 \mathrm{~B})>$ Fujian $(\$ 7.59 \mathrm{~B})>$ Shanghai $(\$ 6.81 \mathrm{~B})>$ Beijing (\$5.12B), respectively. Obviously, Guangdong far exceeded other provinces regarding the inbound tourists and tourism foreign exchange. For the domestic tourists (DT), the top 5 provinces in 2017 were: Shandong $(763.74 \mathrm{M})>$ Jiangsu $(742.87 \mathrm{M})>$ Guizhou $(740.00 \mathrm{M})>$ Sichuan $(670.00 \mathrm{M})>$ Henan $(662.04 \mathrm{M})$, respectively. As to the domestic tourism income (DTI), the top 5 provinces in 2017 were: Jiangsu ( $¥ 1130.75 \mathrm{~B})>$ Guangdong ( $¥ 1066.70 \mathrm{~B})>$ Sichuan ( $¥ 882.54 \mathrm{~B})>$ Zhejiang $(¥ 871.72 \mathrm{~B})>$ Shandong $(¥ 842.07 \mathrm{~B})$, respectively.

Table 3 Top 5 provinces of IT, TFE, DT and DTI in 2017 in China

\begin{tabular}{cccccccc}
\hline Province & IT/million & Province & TFE/ billion & Province & DT/million & Province & DTI/¥billion \\
\hline Guangdong & 36.48 & Guangdong & 19.65 & Shandong & 763.74 & Jiangsu & 1130.75 \\
Shanghai & 8.73 & Zhejiang & 8.28 & Jiangsu & 742.87 & Guangdong & 1066.70 \\
Fujian & 6.92 & Fujian & 7.59 & Guizhou & 740.00 & Sichuan & 882.54 \\
Yunnan & 6.68 & Shanghai & 6.81 & Sichuan & 670.00 & Zhejiang & 871.72 \\
Zhejiang & 5.89 & Beijing & 5.12 & Henan & 662.04 & Shandong & 842.07 \\
\hline
\end{tabular}

As shown in Table 4, the top 5 provinces of growth ratio of inbound tourists from 2008 to 2017 were Tianjin $(600 \%)>$ Tibet $(405 \%)>$ Sichuan $(381 \%)>$ Hunan $(354 \%)>$ Ningxia $(353 \%)$, respectively. Moreover, the top 5 provinces of growth ratio of tourism foreign exchange from 2008 to 2017 were Ningxia $(1396 \%)>$ Xinjiang $(676 \%)>$ Sichuan $(574 \%)>$ Tibet $(536 \%)>$ Anhui $(431 \%)$, respectively. For the growth ratio of domestic tourists from 2008 to 2017, the top 5 provinces were Tibet $(1060 \%)>$ Gansu $(863 \%)>$ Guizhou $(808 \%)>$ Jiangxi $(614 \%)>$ Anhui $(530 \%)$, respectively. As to the growth ratio of domestic tourism income from 2008 to 2017 , the top 5 provinces were Tibet $(1697 \%)>$ Jiangxi $(1088 \%)>$ Gansu $(1057 \%)>$ Hebei $(1037 \%)>$ Yunnan $(1024 \%)$, respectively.

Table 4 Top 5 provinces of growth ratio of IT, TFE, DT and DTI from 2008 to 2017 in China

\begin{tabular}{|c|c|c|c|c|c|c|c|}
\hline \multicolumn{2}{|c|}{ Inbound tourists } & \multicolumn{2}{|c|}{ Tourism foreign exchange } & \multicolumn{2}{|c|}{ Domestic tourists } & \multicolumn{2}{|c|}{ Domestic tourism income } \\
\hline Province & Growth ratio & Province & Growth ratio & Province & Growth ratio & Province & Growth ratio \\
\hline Tianjin & $600 \%$ & Ningxia & $1396 \%$ & Xizang & $1060 \%$ & Xizang & $1697 \%$ \\
\hline Tibet & $405 \%$ & Xinjiang & $676 \%$ & Gansu & $863 \%$ & Jiangxi & $1088 \%$ \\
\hline Sichuan & $381 \%$ & Sichuan & $574 \%$ & Guizhou & $808 \%$ & Gansu & $1057 \%$ \\
\hline Hunan & $354 \%$ & Xizang & $536 \%$ & Jiangxi & $614 \%$ & Hebei & $1037 \%$ \\
\hline Ningxia & $353 \%$ & Anhui & $431 \%$ & Anhui & $530 \%$ & Yunnan & $1024 \%$ \\
\hline
\end{tabular}

\section{Characteristics in different stages}

According to the characteristics of China's tourism development in different times, as shown in Figure 8, this study divides the tourism development of China in the past 40 years into four stages, namely, the initial modern tourism stage, the domestic tourism cultivating stage, 


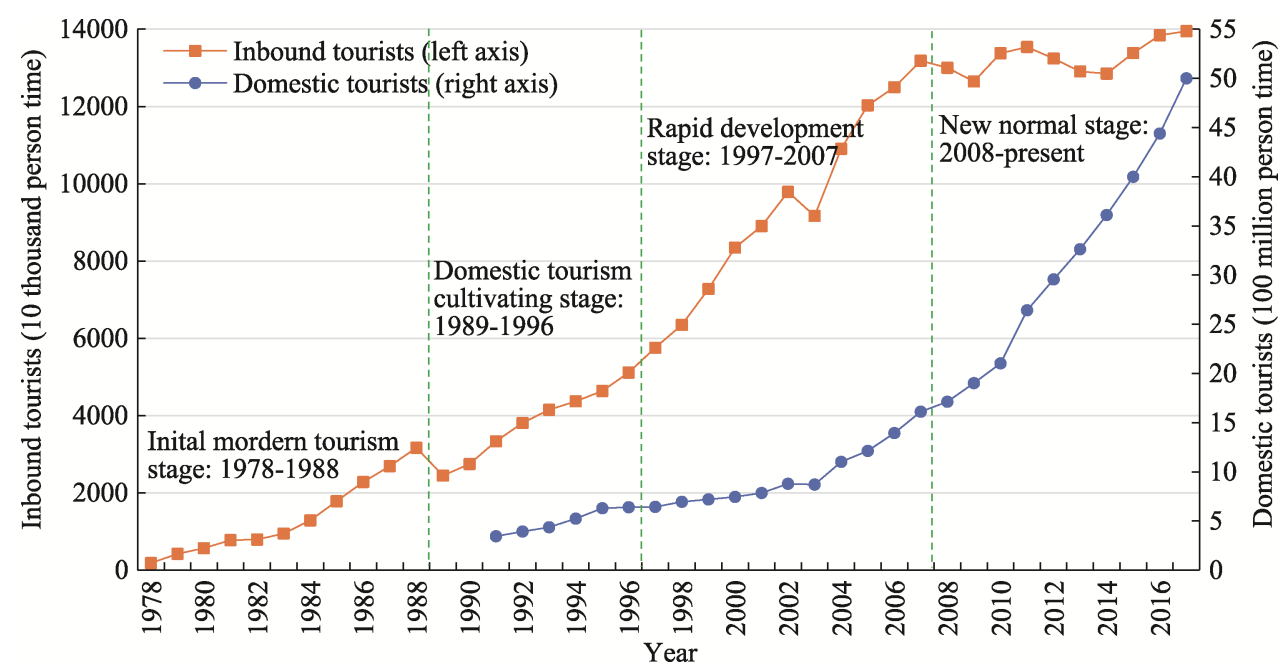

Figure 8 Division of tourism development stages in China

the rapid development stage and the new normal stage.

\subsection{The initial modern tourism stage: from 1978 to 1988}

The year of 1978 is the start of China's modern tourism. In March of the year, the central government of China reorganized the Administration of China's Traveling and Tourism into the China National Tourism Administration (CNTA) that was under the charge of the Ministry of Foreign Affairs. At the same time, all provinces (including autonomous regions and municipalities) were required to set up tourism bureaus. In October of 1978, Deng Xiaoping pointed out that "the two industries of civil aviation and tourism are very worthwhile to do", "civil aviation and tourism should be managed by means of economic management, and profits shall be made from these two industries" The attribute of Chinese tourism has changed from "foreign affairs reception" to "an important industry" ( $\mathrm{Du}, 2012)$. In December of 1978, with the convening of the Third Plenary Session of the 11th Central Committee, China's policy of reform and opening-up officially started, and China's tourism development entered a new stage. On the one hand, improving foreign exchange earnings was still the main goal in this stage, while domestic tourism was not valued. Deng Xiaoping put forward the target of "earning $\$ 10$ billion foreign exchange by the end of the 20th century", coupled with the great attraction of China's natural scenery, history and culture to foreign tourists, inbound tourism developed very rapidly. As a result, a golden tourism line of "Guangdong-Guilin-Beijing-Xi'an-Shanghai" was developed. The inbound tourists increased from 1.8 million in 1978 to 31.69 million in 1988, and foreign exchange earnings increased from $\$ 263$ million to $\$ 2.247$ billion during this period. On the other hand, China's tourism industry was developing towards modernization, openness and integration. As the first joint-venture hotel, Beijing Jianguo hotel opened in 1982, as the first Chinese-foreign five-star hotel, White Swan hotel opened in 1983, and the standard of Classification and Evaluation of Stars of Foreign-related Tourism Hotels was promulgated in 1987. Moreover, as the first large-scale amusement park in the mainland of China, Zhongshan-Changjiang paradise opened in 1983. As the first golf course in the mainland of China, Zhongshan hot spring golf club opened to the public in 1984. In 1985, the State Council of China formally 
promulgated the Interim Regulations on the Administration of Travel Agencies; in 1987, the CNTA formulated the Interim Regulations on the Administration of Tourist Guides. China's modern tourism education also started in this period (Bao, 2009). Generally, this stage is the beginning and foundation stage of China's modern tourism.

The characteristics of tourism geographical pattern in this stage are as follows: inbound tourism was severely polarized, and Guangdong played an essential role in this polarized pattern. In this stage, the Gini coefficient of inbound tourists is above 0.75 , indicating a severely polarized distribution. In addition, hot spot analysis on clustering of provinces found that all high-level provinces are located in the southeastern coastal area of China. Guangdong is the only province in the first tier. In this stage, the second tier included at least four provinces, as shown in Figure 9a, and at most six provinces, as shown in Figure 9b; and the third tier had the largest number of provinces. Guangdong, as the front line of reform and opening-up, coupled with its geographical relationship with Hong Kong and Macao, has long led China's inbound tourism. As the political and economic centers of China, respectively, Beijing and Shanghai naturally have a strong attraction to inbound tourists, and they have long been in the first and second places in the second tier.
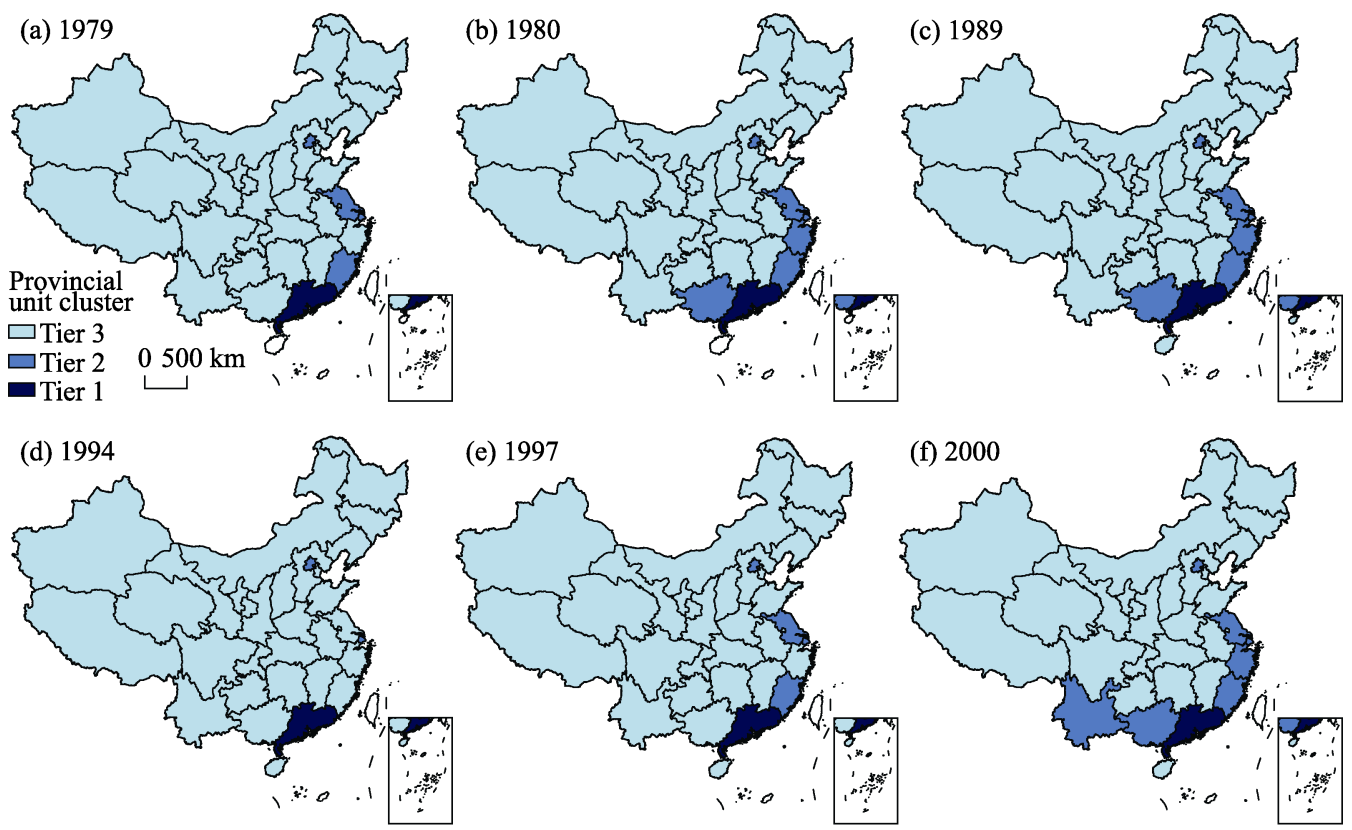

(e) 1997

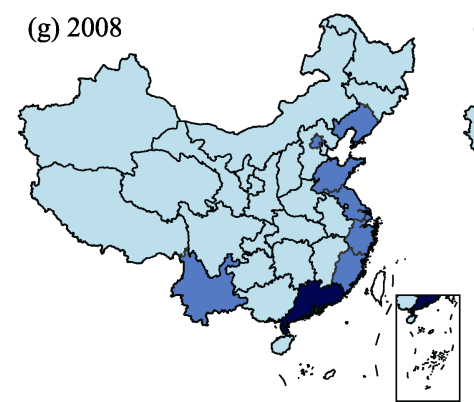

(h) 2017
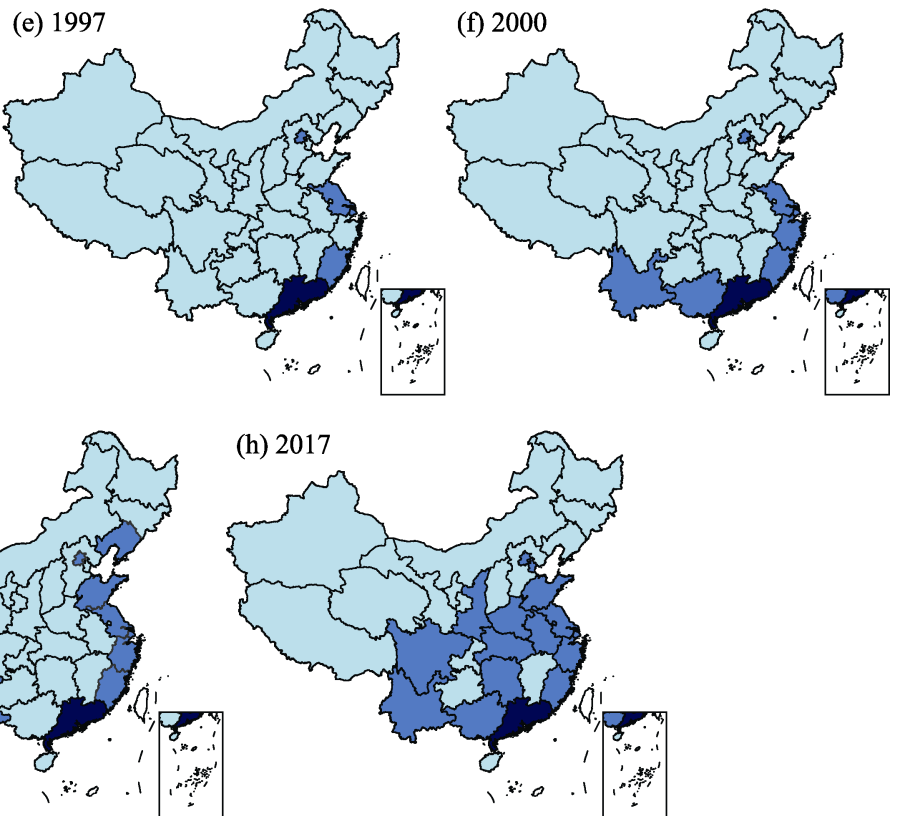

Figure 9 Hot spot analysis clustering of inbound tourist in provincial level districts of China 


\subsection{The domestic tourism cultivating stage: from 1989 to 1996}

The "political disturbance" in 1989 caused a heavy blow to China's inbound tourism. The inbound tourists dropped by $23 \%$, and China's tourism development entered a new stage in 1989. At the beginning of the 1990s, expanding domestic demand became a vital direction for national economic development. Therefore, as a necessary means of expanding domestic demand, domestic tourism became an indispensable part of China's tourism. In 1991, the provinces gradually added domestic tourism statistics into their yearly statistics. Before that, due to the emphasis on inbound tourism, official domestic tourism statistics were rarely found. In 1993, the State Council of China circulated the Opinions on Actively Developing Domestic Tourism issued by the CNTA and put forward the guidelines of "invigorating the market, leading correctly, strengthening management and improving quality" for domestic tourism. In the same year, the CNTA commissioned the National Bureau of Statistics to conduct a sample survey on the domestic tourism situation of urban residents every year, from then on domestic tourism began to be formally included in the regular statistics. In 1995, the system of "two-day weekend" began to implement. As a consequence, the leisure time for residents increased, and the domestic tourism market prospered further. The domestic tourists grew from 340 million in 1991 to 640 million in 1996. At the same time, inbound tourists increased steadily from 24.514 million in 1989 to 51.127 million in 1996 .

In this stage, the characteristics of tourism geographical pattern are as follows: the spatial structure of inbound tourism remains unchanged, and Fujian developed rapidly in inbound tourism. Hot spot analysis on clustering of provinces revealed that Guangdong was still the only province in the first tier, the second tier included six provinces at most, as shown in Figure 9c, and two provinces at least, as shown in Figure 9d; and other provinces were all included in the third tier. Briefly, there was no fundamental change in spatial structure, compared with the previous stage. Guangdong, Beijing and Shanghai were the top three destinations for inbound tourists. In the second tier, Fujian surpassed Jiangsu and Guangxi, becoming the province with the fourth largest number of inbound tourists after Guangdong, Beijing and Shanghai. This situation was related to the easing of cross-strait relations during this stage. In particular, the establishment of the Straits Exchange Foundation, the Association for Relations across the Taiwan Straits and the "1992 consensus" created a relatively smooth political environment for Taiwan tourists to enter the mainland of China.

Furthermore, domestic tourism presented a pattern of polarization, and Beijing took first place in domestic tourism. In this stage, the Gini coefficient of domestic tourists was on the high side, above 0.4 , indicating that the distribution was polarized nationwide. Through the hot spot analysis, this article found that there was no "polar core" for domestic tourists, with Beijing and Shanghai taking the first place and the second place in domestic tourists, respectively. The first tier included two provinces at least, as shown in Figure 10a, and eight provinces at most, as shown in Figure 10b. As for the number of provinces, the first tier had fewer provinces than the second tier, and the third tier had fewest provinces.

\subsection{The rapid development stage: from 1997 to 2007}

In 1997, the Asian financial crisis caused a severe blow to the economies of Asian countries, including China. However, the tourism industry in China was not affected much and grew steadily rather than fell. From this point, China's tourism industry had entered the rapid 

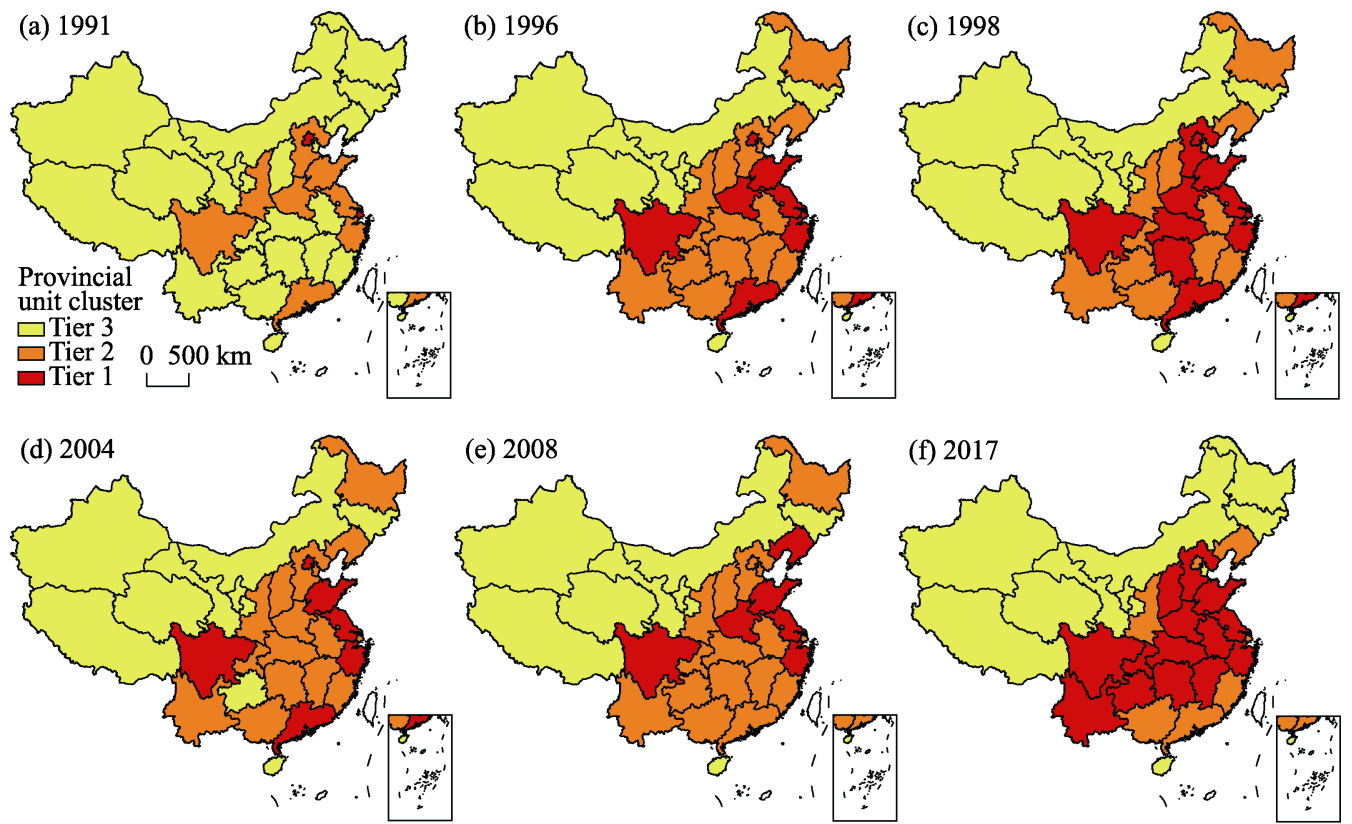

Figure 10 Hot spot analysis clustering of domestic tourist in provincial level districts of China

development stage. The return of Hong Kong in 1997 and the return of Macao in 1999 had broadened the entrance to China's inbound tourism and opened up essential exits for outbound tourism. The establishment of the "Golden Week" system in 1999 added a catalyzer to domestic tourism. In 1999, online travel agency represented by Ctrip was set up to provide service support for self-help traveling in China. In 2000, the per capita GDP of China exceeded $\$ 1000$, and domestic tourism began to grow amazingly fast. China's entry into the World Trade Organization in 2001 accelerated the reform of the domestic economic system and promoted standardization of tourism services and competition of the tourism market objectively. In this stage, the domestic tourists increased from 644 million in 2001 to 1.61 billion in 2007, the inbound tourists increased from 57.5879 million to 132 million, and the outbound tourists increased from 5 million to 40.954 million.

The characteristics of tourism geographical pattern in this stage are as follows: Shanghai gradually replaced the status of Beijing's inbound tourism. By the hot spot analysis, this article found that only Guangdong was in the first tier; the second tier had at least four provinces, as shown in Figure 9e; at most seven provinces, as shown in Figure 9f; the other provinces were at the third tier. At the second tier, Shanghai gradually replaced Beijing as the primate city in inbound tourism; by the end of this stage, Beijing had already ranked behind Shanghai, Jiangsu and Zhejiang.

The distribution of domestic tourism was relatively balanced in the gross, and the upper tier provinces mainly located in southeastern China. In this stage, the Gini coefficient of domestic tourists at the national-scale dropped to below 0.4 , indicating a gradually balanced distribution throughout the country. By the hot spot analysis, this article found that the provinces of the first and second tiers are mainly located in the southeast of China, and the northwest regions were in the third tier. At the first tier, there were at most 11 provinces, as shown in Figure $10 \mathrm{c}$, and at least 6 provinces, as shown in Figure 10d. In terms of the number of provinces, the second tier had the most significant number of provinces. By the end of this stage, Ji- 
angsu and Shandong had taken the place of Beijing and Shanghai in domestic tourism.

\subsection{The new normal stage: from 2008 to present}

Influenced by the American financial crisis, the global economy shrank in 2008. China's tourism industry was also affected, and inbound tourism continued to decline in 2008 and 2009. Although impacted by the financial crisis, the domestic tourism of China increased by $6.3 \%$ compared with that in 2007 , and it showed a strong anti-interference capability. In addition, with the opportunity of hosting the Beijing Olympic Games, the Shanghai World Expo and the Guangzhou Asian Games, China showed the world a new look and attracted about 130 million inbound tourists that got the highest level in history. Since then, China's tourism development had entered the new normal stage. In 2008, China's per capita GDP exceeded $\$ 3000$, and outbound travel demand was strong. In the same year, Chinese outbound tourists became the focus of media in various countries. Because of their strong purchasing power, Chinese tourists became a source market competed by many countries. In 2013 , with the per capita GDP exceeding $\$ 7000$, China became the country with the highest outbound tourism consumption. The "Eight Provisions" promulgated in 2012 and the Notice on Prohibiting Party and Government Organs from Meeting in Scenic Spots issued in 2014 curbed "public-funded tourism" and hit the "luxury" of tourism consumption to a great extent. Although domestic tourism maintained rapid growth, the way tourists consume gradually shifted to budgeted consumption (Bao, 2015). In short, China had entered a new normal stage in domestic tourism since 2008, inbound tourism and outbound tourism.

In this stage, the geographical pattern of tourism featured as the improvement of the spatial structure of inbound tourism and the inbound tourist entering the era of million person-times. Statistics showed that more than half of the provinces in this stage had crossed the threshold of 1 million inbound tourists, and the total number of inbound tourists had almost exceeded 130 million in China. After the hot spot analysis, it indicated that the second tier included 8 provinces at least, as shown in Figure 9g, and 15 provinces at most, as shown in Figure $9 \mathrm{~h}$. The second tier, which previously covered only the southeastern coastal provinces, had extended to include some central and western provinces, such as Yunnan, Shaanxi, Hubei, Anhui, Sichuan, Hunan and Henan.

The first tier provinces of domestic tourism increased significantly, and the third tier provinces were relatively fixed. After the hot spot analysis, it found that the first tier included at least 6 provinces, as shown in Figure 10e and at most 14 provinces, as shown in Figure 10f. Moreover, Shandong, Jiangsu, Sichuan, Henan and Zhejiang have long been in the first tier, while Beijing and Shanghai have been excluded from the first tier and included into the second tier. Generally speaking, the number of provinces in the second tier is the largest, but there is a decreasing trend. The number of provinces in the first tier is increasing. The provinces in the third tier were relatively fixed, with Gansu, Jilin, Inner Mongolia, Xinjiang, Hainan, Qinghai, Ningxia, Tibet included in the third tier for a long time.

Outbound tourism grew steadily. Beijing and Shanghai led outbound tourism consumption. During this period, the outbound tourists reached 45.84 million in 2008 and 129 million in 2017 , which was 2.8 times that of 2008 , with an average growth rate of $12.18 \%$. Outbound tourism consumption reached $\$ 29$ billion in 2008, peaking at $\$ 128.7$ billion in 2013, and $\$ 115.29$ billion in 2017. Since 2013, the outbound tourism consumption of China has ranked first in the world, with an average growth rate of $16.57 \%$. In 2017, Beijing, Shanghai, 
Suzhou, Wenzhou, Shenyang, Changchun, Dalian, Qingdao, Guiyang and Jinan were among the top ten cities in terms of per capita consumption. Beijing has the highest amount of per capita outbound tourism consumption, averaged at 6817 yuan (RMB), equivalent to about $\$ 1000$ (CTA, 2017).

\section{Influencing factors}

\subsection{Qualitative analysis}

\subsubsection{Policies}

Based on the particular national conditions of China, policy support and guidance of the government play a vital role in the development of tourism in China. Before the reform and opening-up, tourism was mainly about foreign affairs reception, instead of a real industry. After the reform and opening-up, marked by Deng Xiaoping's "five speeches on tourism," China's foreign tourism reception has formally transformed into a modern industry. As mentioned above, at the beginning of reform and opening-up (1978-1988), inbound tourism was mainly intended for foreign exchange earnings and still marked by "quota supply." Subsequently, the government attached more importance to the tourism industry. In 1992, the Chinese central government pointed out that tourism was the principal industry in the tertiary industry. After that, tourism was listed as the first industry in the tertiary industry to actively develop new industries according to Advice on Ninth Five-Year Plan for Economic and Social Development and the Outline of Vision 2010. In 1998, the central economic work conference put forward tourism as a new growth point of the national economy. In 2009, the Opinions on Accelerating the Development of Tourism pointed out that tourism should be cultivated into a strategic pillar industry of the national economy and a more satisfactory modern service industry for the people. In short, China's tourism industry has undergone a transformation from reception to a foreign exchange earning industry, and then to a strategic pillar industry.

\subsubsection{Management system}

In 1981, the tourism industry implemented a unified leadership and decentralized management system. Unified leadership is unified planning, policy, system, discipline and coordination; decentralized management means division of responsibility and hierarchical management under the premise of unified leadership. In 1984, the situation that non-tourism sectors were not allowed to run the tourism business was broken down, and the power of outreach and visa control was decentralized. All provinces, autonomous regions and municipalities directly under the central government had the power of outreach. In 1988, the principle of "regulating the market by the state and guiding the enterprises by the market" established. The tourism industry experienced shifts from administrative management to industry management and from direct management of enterprises to indirect management and regulation through the market. In 1994, the CNTA further delegated to the local authorities the power of examination and approval of travel agencies and the power of star-rating assessment of foreign-related tourism hotels. In 1998, the CNTA no longer retained the functions for administration of foreign exchange, tourism planning and tourism price. Tourism development is left to the market further. Entering the new era, the market began to play a fundamental role in the allocation of resources to a greater extent and in a broader range. Recently, the "fundamental role" of the market becomes the "decisive role" in allocating resources. In a 
word, the administration of China's tourism shifted from relative centralization to relative decentralization and now to a stage of full marketization.

\subsubsection{Tourism demand}

Experience shows that the development of tourism in a country or region will usually shift from sightseeing tourism to vacation tourism and from domestic tourism to international tourism (Chen, 2014). When the per capita GDP of a country reaches $\$ 800-\$ 1,000$, the residents will generally generate a domestic tourism motivation; when the per capita GDP reaches $\$ 4,000-\$ 10,000$, people will have a motivation for international tourism; when the per capita GDP reaches more than $\$ 10,000$, it will stimulate the development of intercontinental tourism (Sun, 1990). China's tourism development also follows the path of "domestic sightseeing tourism to domestic leisure and vacation tourism, and then to outbound tourism." Moreover, China's tourism had developed into diversified forms of tourism, such as vacation tourism, folk culture tourism, ecological tourism, sports tourism, photography tourism, Buddhist meditation tourism, in addition to merely sightseeing and visiting friends and relatives in the early stage. China's tourism has become not only diversified and individualized in form but also higher and deeper in level.

\subsection{Quantitative analysis}

\subsubsection{Factors affecting tourism at national-scale}

This study used SPSS 22.0 to test the Pearson correlation coefficients between domestic and inbound tourists and other macro-data at the national-scale from 1991 to 2017. As shown in Table 1, this study examines the impact of eight factors on domestic tourism and inbound tourism, namely, economic level, consumption level, industrial development, investment status, traffic conditions, accommodation services, intermediary services and degree of openness, with 15 specific variables.

Table 1 Correlation analysis of factors influencing tourism at national scale in China

\begin{tabular}{|c|c|c|c|}
\hline Factors & Variables & Domestic tourists & Inbound tourists \\
\hline Economic level & GDP & $0.996 * *$ & $0.809 * *$ \\
\hline \multirow[t]{2}{*}{ Consumption level } & Per capita GDP & $0.995 * *$ & $0.815^{* *}$ \\
\hline & Total retail sales of social commodities & $0.998 * *$ & $0.769 * *$ \\
\hline \multirow[t]{2}{*}{ Industrial development } & Third industry proportion & $0.922 * *$ & $0.880 * *$ \\
\hline & Third industry output value & $0.998 * *$ & $0.775^{* *}$ \\
\hline Investment status & Investment in fixed assets & $0.996 * *$ & $0.738 * *$ \\
\hline \multirow[t]{5}{*}{ Traffic conditions } & Railway mileage & $0.991 * *$ & $0.810 * *$ \\
\hline & Road mileage & $0.909 * *$ & $0.928 * *$ \\
\hline & Civil aviation domestic routes & $0.985 * *$ & $0.752 * *$ \\
\hline & Civil aviation international routes & $0.967 *$ & $0.783 * *$ \\
\hline & Civilian passenger vehicle & $0.994 * *$ & $0.722 * *$ \\
\hline Accommodation services & Number of rooms in star hotels & $0.754 * *$ & $0.984 * *$ \\
\hline Intermediary services & Travel agency scale & $0.918 * *$ & $0.959 * *$ \\
\hline \multirow[t]{2}{*}{ Degree of openness } & Use of foreign capital & $0.515 * *$ & $0.817 * *$ \\
\hline & Import and export volume & $0.938 * *$ & $0.903 * *$ \\
\hline
\end{tabular}

Note: $*$ indicates significant at the $5 \%$ level, ** indicates significant at the $1 \%$ level. 
For domestic tourism, the eight factors highly correlated with the number of domestic tourists. Except for the correlation coefficient between the number of guest rooms in star hotels and the number of domestic tourists, the correlation coefficients between the other 13 variables and the number of domestic tourists exceeded 0.9, showing a high correlation. For inbound tourism, the eight factors are strongly correlated with the number of inbound tourists. However, the correlation coefficients of the other 11 variables with the number of inbound tourists are less than 0.9 except for the four variables of "road mileage," "number of rooms in star hotels," "travel agency scale" and "import and export volume." The four factors, i.e. traffic conditions, accommodation services, intermediary services and the degree of openness, have the greatest impact on inbound tourism.

5.2.2 Factors affecting tourism at provincial level

At the provincial level, as shown in Table 2, this study examines the impact of nine factors on domestic tourism and inbound tourism of provincial level districts in 2015, including tourism attraction, economic level, consumption level, industrial development, investment status, traffic conditions, accommodation services, intermediary services and degree of openness. There are 15 specific variables.

Table 2 Correlation analysis of factors influencing tourism at provincial-scale in China

\begin{tabular}{llcc}
\hline \multicolumn{1}{c}{ Factors } & \multicolumn{1}{c}{ Variables } & Domestic tourists & Inbound tourists \\
\hline Tourist attractions & Scenic spots & $0.621^{* *}$ & $0.573^{* *}$ \\
& High-grade scenic spots & $0.721^{* *}$ & 0.201 \\
Economic level & Provincial GDP & $0.693^{* *}$ & $0.594^{* *}$ \\
Consumption level & Per capita GDP & 0.080 & 0.232 \\
Industrial development & Tertiary industry income & $0.627^{* *}$ & $0.637^{* *}$ \\
Investment status & Investment in fixed assets & $0.832^{* *}$ & 0.263 \\
Accommodation services & Number of accommodations & $0.650^{* *}$ & $0.730^{* *}$ \\
& Number of restaurants & $0.676^{* *}$ & $0.635^{* *}$ \\
Intermediary services & Total number of travel agents & $0.637 * *$ & $0.461^{* *}$ \\
Traffic conditions & Number of private cars & $0.707^{* *}$ & $0.507^{* *}$ \\
& Railway passenger volume & $0.650^{* *}$ & $0.645^{* *}$ \\
& Highway passenger volume & $0.638^{* *}$ & 0.321 \\
Degree of openness & Civil aviation passenger volume & 0.136 & $0.808^{* *}$ \\
\hline
\end{tabular}

Note: $*$ indicates significant at the $5 \%$ level, ** indicates significant at the $1 \%$ level.

For domestic tourism, three variables, i.e. "per capita GDP," "civil aviation passenger volume" and "import and export volume" of each province do not correlate with domestic tourist volume. The correlation coefficient between "high-grade scenic spots," "investment in fixed asset," "number of private cars" and domestic tourist volume is more than 0.7 , which indicates that the three factors of the tourist attractions, investment status and traffic conditions highly correlate with domestic tourism. For inbound tourism, there is no correlation to "high-grade scenic spots," "per capita GDP," "investment in fixed asset" and "highway passenger volume." The correlation coefficients between "number of accommodations," "civil aviation passenger volume" and "import and export volume" exceeded 0.7 , indicating that accommodation services, traffic conditions and degree of openness highly correlate with 
inbound tourism.

Of course, besides the factors mentioned above, the climate can also influence the length and fluctuation of the tourism seasonality (Lu et al., 2002; Tao et al., 2015; Liu et al., 2016). Water resource can affect the carrying capacity of a tourist destination (Wang et al., 2009; Liu et al., 2018). Geomorphic features and water system can also influence the distribution of tourism resources (Wang et al., 2017; Wu et al., 2017). But this article mainly aims to discuss the socio-economic factors that influence China's tourism development, and we will not analyze the natural factors here.

\section{Discussion}

Both domestic tourism and inbound tourism show "high in the eastern and low in the western part; high in the southern and low in the northern part." This characteristic is very similar to the finding by Li et al. They compared the overall efficiency of tourism of 2012 with that of 2013, and found that the overall efficiency of China's tourism presented the pattern of "high in the eastern and low in the western part; high in the southern and low in the northern part" (Li et al., 2017). However, this present article analyzed 40-year data to discover the pattern instead of cross-section data. Therefore, the overall characteristic of China's tourism geographical pattern in this article is convinced.

Tourism is a changing phenomenon with the development of itself; therefore, every development stage will present more or less different characteristics. This article summarized the history of China's tourism in the past 40 years and divided it into four stages. In the initial modern tourism stage, the government's attention was on inbound tourism; in the domestic tourism cultivating stage, domestic tourism could gradually develop; in the rapid development stage, the inbound and domestic tourism both developed dramatically, and by the new normal stage, the outbound tourism also stepped into the new era together with inbound and domestic tourism. Although these are just background for introducing the tourism geographical pattern in every stage, they can show some information to readers who want to understand the brief history of China's tourism. It is noteworthy that the division of China's tourism development in this article is different from the viewpoint of Xia and Xu's. They divided it into three periods: the period of opening-up and preliminary reform (1978-1991), the period of the internal opening and accelerative reform (1992-2011) and the period of two-way opening and deepening reform (2012-present) (Xia et al., 2018). However, they only referred to the domestic policies on tourism to divide without considering the influence of international events. In this article, we took into account the impact of domestic and international events on China's tourism. Therefore, our four-stage division is more credible.

This article mainly analyzed the spatial pattern of inbound tourist and domestic tourist and made some sense to China's tourism. However, the provincial-level outbound tourist data are challenging to collect. Therefore, the limitation of this article is that the geographical pattern is only applicable to depict inbound and domestic tourism. In the future, adding the analysis of outbound tourist of every province to supplement this research is a desirable research direction. The other limitation is that we only analyzed the socio-economic factors, not the natural factors which could influence tourism development. In reality, tourism as an industry is undoubtedly affected by natural factors, such as air temperature, rainfall and altitude. Therefore, taking social, economic and natural factors into account to depict the integrated influence on tourism is the next research proposal. 


\section{Conclusions}

This article simultaneously employed inbound tourist data and domestic tourist data to analyze the spatiotemporal pattern of China's tourism from a national-scale perspective and 40 -year time-scale perspective. The main contributions lie in using multiple tourism data and finding the overall features and stage characteristics for China's tourism. The main conclusions are as follows:

In the past 40 years of reform and opening-up, the overall characteristics of China's tourism geographical pattern are "high in the eastern, low in the western part; and high in the southern, low in the northern part." Inbound tourism polarized for a long time, and Guangdong is the "polar core" of inbound tourism. Domestic tourism has experienced a process from polarized distribution to equilibrium distribution, and the primacy distribution of domestic tourists is not significant. In addition, the development of tourism differs significantly within eastern, central, western, southern and northern regions.

In the past 40 years, China's tourism development could be divided into four stages, they are the initial modern tourism stage (1978-1988), the domestic tourism cultivating stage (1989-1996), the rapid development stage (1997-2007) and the new normal stage (2008-present), respectively. In the initial modern tourism stage, inbound tourism presented a severe polarization, and Guangdong played an essential role in forming that polarization. When it entered into the domestic tourism cultivating stage, inbound tourism spatial structure remained unchanged (Guangdong the first, Beijing the second, Shanghai the third), and the domestic tourism featured a polarized distribution by and large. When it stepped into the rapid development stage, the status of inbound tourism in Beijing was gradually replaced by Shanghai, and the distribution of domestic tourism balanced in principle. By the new normal stage, the spatial structure of inbound tourism significantly improved, and the number of provinces in the first tier of domestic tourism increased a lot. Likewise, outbound tourism increased rapidly in the new normal stage, and Beijing and Shanghai led the per capita consumption of outbound tourism.

The factors that affect the tourism geographical pattern in China are diverse. From the perspective of qualitative analysis, policies, management system and tourism demand affect the development of tourism in China. From the perspective of quantitative analysis, tourist attractions, economic level, consumption level, industrial development, investment status, traffic conditions, accommodation services, intermediary services and the degree of openness have different degrees of impact on domestic tourism and inbound tourism.

\section{References}

ArcGIS, 2018. How hot spot analysis (Getis-Ord Gi*) works. http://desktop.arcgis.com/en/arcmap/10.3/tools/ spatial-statistics-toolbox/h-how-hot-spot-analysis-getis-ord-gi-spatial-stati.htm.

Bao J G, 2009. From idealism to realism to rational idealism: Reflection on 30 years of development in tourism geography in China. Acta Geographica Sinica, 64(10): 1184-1192. (in Chinese)

Bao J G, 2015. Budgeted consumption and China's tourism development. Tourism Tribune, 30(2): 1-3. (in Chinese)

Cao F D, Huang Z F, Wu J, 2012. The space-time pattern evolution and its driving mechanism of urban tourism development efficiency: A case study of Pan-Yangtze River Delta. Geographical Research, 31(8): 1431-1444. (in Chinese)

Chen H, Lu L, Zheng S T, 2011. The tourism spatial pattern evolution of the Pearl River Delta. Acta Geographica Sinica, 66(10): 1427-1437. (in Chinese)

Chen Y C, Guo J, Xu H, 2014. Leisure tourism: Research status, difference and connotation exploration. Geog- 
raphy and Geo-information Science, 30(6): 94-98. (in Chinese)

China Tourism Administration (CTA), Ctrip T G, 2018. China outbound tourism big data report 2017. http://www.ctaweb.org/html/2018-2/2018-2-26-11-57-78366.html.

Du Y L, 2012. Understanding Deng Xiaoping's strategic thinking on tourism. Literature of Chinese Communist Party, (6): 57-61. (in Chinese)

Guo Y R, Zhang J, Lu S J et al., 2014. Spatio-temporal change of the inbound tourism economic development in China. Scientia Geographica Sinica, 34(11): 1299-1304. (in Chinese)

He B Q, Hong X J, 2016. A review of research on calculation and decomposition methods of Gini coefficient. Statistics \& Decision, (14): 13-17. (in Chinese)

Huang Y F, Ma Y F, Xue H J, 2013. Spatio-temporal-situational evolution and regional influencing factors of the inbound tourism service quality in China. Acta Geographica Sinica, 68(12): 1689-1701. (in Chinese)

Lei Z M, Kang J J, 2010. Evaluation theory of urban primacy: Theoretical framework and empirical analysis. Urban Studies, 17(4): 33-38. (in Chinese)

Li C X, Ma Y F, Zhang Y et al., 2012. Dynamic evolution mode of regional dominance indexes of Chinese inbound tourism flows during 1993 to 2008: An empirical research based on modified entropy technology. Geographical Research, 31(2): 257-268. (in Chinese)

Li Z F, Ye Y D, Gao J N, 2017. Efficiency evaluation and agglomeration characteristics analysis of tourism industry in China. Statistics \& Decision, (1): 139-141. (in Chinese)

Li Z J, Guan W H, Pu Y X et al., 2013. Exploration on the tourism economy spatio-temporal pattern in Shandong province. Economic Geography, 33(7): 176-181. (in Chinese)

Liu F J, Zhang J, Chen D D, 2010. The characteristics and dynamical factors of Chinese inbound tourist flow network. Acta Geographica Sinica, 65(8): 1013-1024. (in Chinese)

Liu J, Huang L, Wu L J et al., 2018. Assessment on direct and virtual water consumption of rural tourism in back-mountain of Qingcheng. Tourism Tribune, 33(9): 108-116. (in Chinese)

Liu J, Li Y Y, Liu H L et al., 2016. Climate change and peach blossom viewing: Impact and adaptation. Geographical Research, 35(3): 504-512. (in Chinese)

Lu L, Xuan G F, Zhang J H et al., 2002. An approach to seasonality of tourist flows between coastland resorts and mountain resort: Examples of Sanya, Beihai, Mt. Putuo, Mt. Huangshan and Mt. Jiuhua. Acta Geographica Sinica, 57(6): 731-740. (in Chinese)

Ma R F, Ni X X, Zhang W Z et al., 2015. A multi-scale research on tourism economic spatio-temporal difference in Zhejiang province. Economic Geography, 35(7): 176-182. (in Chinese)

Ma Y F, Li Y J, 2001. Research on spatial region-division of inbound tourist flow in China. Human Geography, 16(6): 44-46. (in Chinese)

Shi C Y, Zhang J, You H M et al., 2007. Core-periphery spatial structure and its evolution of tourism region in Sichuan province. Acta Geographica Sinica, 62(6): 631-639. (in Chinese)

Sun S Q, 1990. Research on Tourism Economy in China. Beijing: People's Publishing House, 1-2. (in Chinese)

Tao Z X, Ge Q S, Wang H J et al., 2015. Phenological basis of determining tourism seasons for ornamental plants in central and eastern China. Journal of Geographical Sciences, 25(11): 1343-1356.

UNWTO, 2001. Tourism 2020 Vision. Madrid: World Tourism Organization.

Wang D G, Niu Y, Qian J, 2018. Evolution and optimization of China's urban tourism spatial structure: A high speed rail perspective. Tourism Management, 64: 218-232.

Wang H Q, Yuan J D, Meng X J, 2017. Spatial distribution and its influencing factors of level-A scenic spots in northeast China. Scientia Geographica Sinica, 37(6): 897-903. (in Chinese)

Wang K, Yi J, Li H, 2014. An analysis of the spatio-temporal disparities of inbound tourism development in China: 1991-2010. Human Geography, 129(1): 134-140. (in Chinese)

Wang Q, Zhang J H, Yang X Z, 2009. Analysis of water ecology capacity in Huangshan resort. Geographical Research, 28(4): 1105-1114. (in Chinese)

Wikipedia, 2018. Gini coefficient. https://en.wikipedia.org/wiki/Gini_coefficient\#Generalized_ineq-uality_indices.

Wu Q, Li X G, Wu L et al., 2017. Distribution pattern and spatial correlation of A-grade tourist attractions in Hunan province. Economic Geography, 37(2): 193-200. (in Chinese)

Xia J C, Xu J H, 2018. Reform and opening-up of tourism in China from 1978 to 2017: Retrospects and prospects. Research on Economics and Management, 39(6): 3-14. (in Chinese)

Yang Y, Wong K K, 2013. Spatial distribution of tourist flows to China's cities. Tourism Geographies, 15(2): $338-363$.

Zhang C H, Ma Y F, Wu J et al., 2013. Coupling coordination degree between inbound tourist flows and destinations and its spatio-temporal differences in the western region of China: A study from the perspective of supply-demand relationship. Economic Geography, 33(10): 174-181. (in Chinese) 